\title{
Leiomyosarcoma in the Posterior Mediastinum Presented as Dumbbell Shape Demonstrated on ${ }^{18}$ F-FDG PET/CT Imaging
}

\author{
Liu Xiao", Wenjie Zhang", Xiaohong Ou and Lin Li* \\ Department of Nuclear Medicine, China
}

*Corresponding author: Lin Li, Department of Nuclear Medicine, China

\section{ARTICLE INFO}

Received: 幽 November 01, 2019

Published: 慧 November 08, 2019

Citation: Liu Xiao, Wenjie Zhang, Xiaohong $\mathrm{Ou}$, Lin Li. Leiomyosarcoma in the Posterior Mediastinum Presented as Dumbbell Shape Demonstrated on ${ }^{18}$ F-FDG PET/CT Imaging. Biomed J Sci \& Tech Res 22(4)2019. BJSTR. MS.ID.003779.

\begin{abstract}
A 63-year-old man complained of the back pain for 2 years. The MRI and ${ }^{18} \mathrm{~F}$-FDG PET/CT demonstrated the mass located in the left posterior mediastinum and invaded the spinal canal through the adjacent intervertebral foramen caused the dumbbell shape. The metabolism of the lesion was low with a $\mathrm{SUV}_{\max }$ as 3.59 on ${ }^{18} \mathrm{~F}-\mathrm{FDG}$ PET imaging. The pathology examination revealed the leiomyosarcoma. This case demonstrated that high-grade leiomyosarcoma in the posterior mediastinal can have low ${ }^{18} \mathrm{~F}-\mathrm{FDG}$ metabolism and dumbbell-shaped tumor in the posterior mediastinal should consider leiomyosarcoma as differential diagnosis.
\end{abstract}

Keywords: Leiomyosarcoma; Dumbbell Shape; Posterior Mediastinum; PET/CT

\section{Case Report}

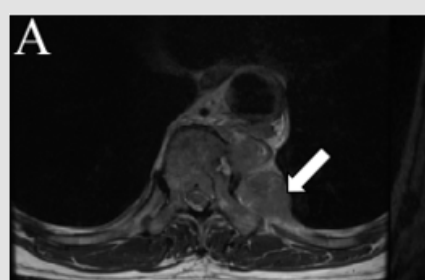

B

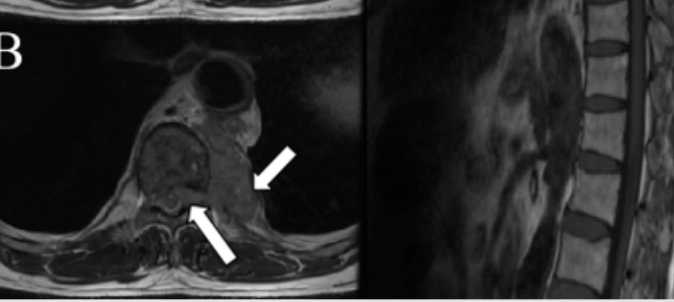

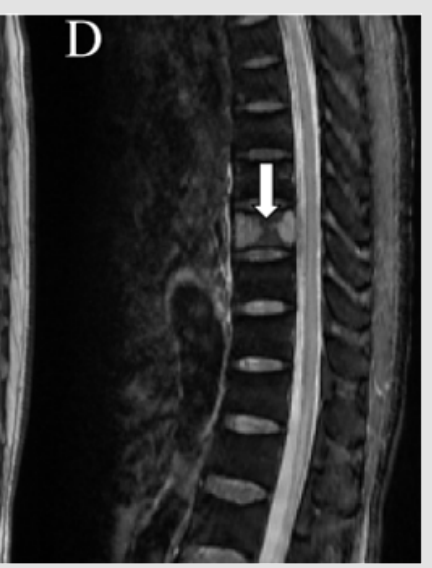

Figure 1: A 63-year-old man complained of the central back pain 2 years. MRI of the throactic vertebre showed the there was a mass located in the left posterior mediastinum with slightly hypointense in T1 weighted image (T1WI) (short arrow in A and B) and invaded the spinal canal through the intervertebral foramen caused the dumbbell shape (long arrow in B: T1WI). The adjacent T10 vertebral body has bone destruction (arrow, C: T1WI, D: T2WI). A malignant tumor was suspected.

The lesion invaded the spinal canal through the intervertebral foramen with adjacent T10 vertebra bone destruction with sclerosis (arrow in E: PET/CT bone fusion imaging), which was diagnosed as suspected malignant neurogenic tumor. In addition, no extra-lesion involvement was observed. Surgical excision of the lesion and vertebral body of T10 was performed. The tumor cells were immu nohistochemically positive for desmin and Caldesmon and negative for SMA, myoD1 and S-100. These findings confirmed the diagnosis of leiomyosarcoma with FNCLCC grade of 3. Primary leiomyosarcoma of the posterior mediastinum is a very rare malignant mesenchyma tumor, which come from the soft tissue of the mediasti- 
num or the great vessels [1]. Dumbbell-shaped tumor is a type of the inner and outer spinal canal tumor and most of these tumors are neurogenic tumors [2] (Figure 1). Some non-neurogenic dumb bell-shaped tumors occurred in posterior mediastinum including angioma, angiolipoma, chondrosarcoma [3], desmiod tumor [2], lymphoma [4], castleman disease [5]. The posterior mediastinal of leiomyosarcoma caused dumbbell-shape is very rare and there was only one case reported in the literature [6]. Intense ${ }^{18} \mathrm{~F}-\mathrm{FDG}$ uptake with $\mathrm{SUV}_{\max }$ from 5 to 28 observed in leiomyosarcoma had been reported in the literature [7-13] and high-grade leiomyosarcoma may correlated with high $\mathrm{SUV}_{\max }[14]$. However, minimal ${ }^{18} \mathrm{~F}-\mathrm{FDG}$ uptake in leiomyosarcoma is noteably rare [1]. Interestingly, our patient had the highest FNCLCC of grade 3 but the SUV max $_{\text {mas }}$ 3.59. This case demonstrated that high-grade leiomyosarcoma in the posterior mediastinal can have low ${ }^{18} \mathrm{~F}-\mathrm{FDG}$ metabolism and dumbbell-shaped tumor in the posterior mediastinal should consider leiomyosarcoma as differential diagnosis (Figure 2).
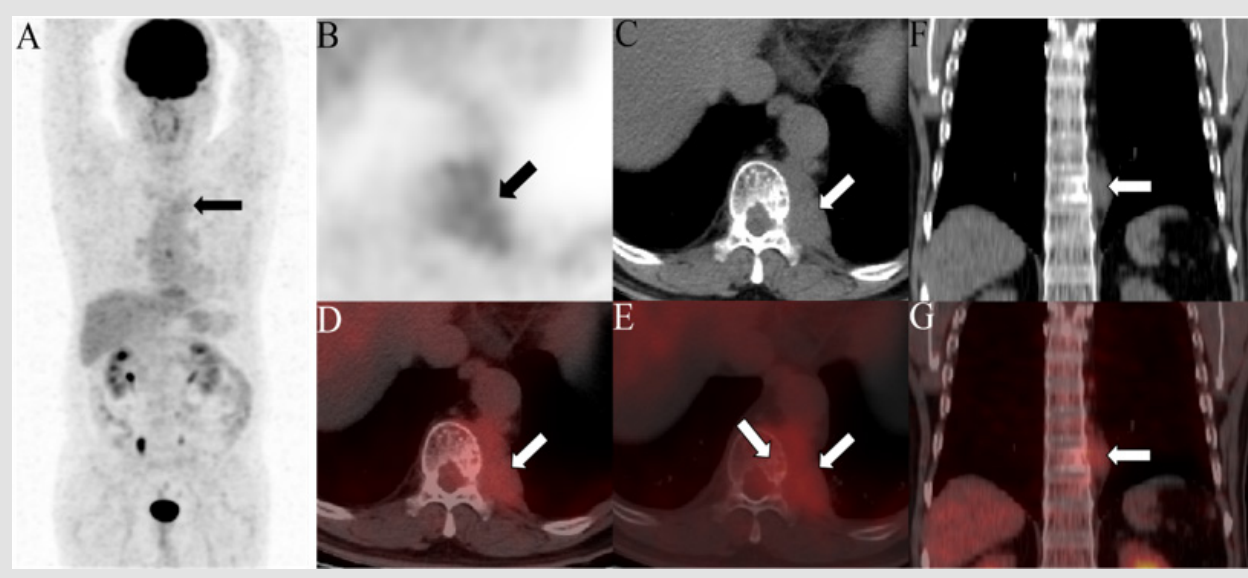

Figure 2: The patient underwent the 18F-FDG PET/CT for tumor staging. The maximum intensity projection (MIP) image (A) demonstrated a minimal radioactivity (arrow) in the left mediastinum. The axial (B: PET, C: CT, D: PET/CT fusion imaging), coronal (F: CT and G: PET/CT fusion imaging) images of the chest displayed a lesion (arrow) with the biggest size of $62 \times 43 \mathrm{~mm}$ and a SUVmax of 3.59 in the left posterior mediastinum.

\section{References}

1. Iijima Y, Akiyama H, Nakajima Y, Kinoshita H, Hirata T (2018) A Case of Primary Mediastinal Leiomyosarcoma in Which Long-Term Survival Was Achieved. Ann Thorac Cardiovasc Surg.

2. Luo N, He X, Li G, Tang Q, Ye R, et al. (2019) Desmoid Tumor Presenting as a Typical Cervical Dumbbell Tumor:A Case Report and Literature Review. World Neurosurg pp. 1878-8750.

3. Ozawa H, Kokubun S, Aizawa T, Hoshikawa T, Kawahara C (2007) Spinal dumbbell tumors: an analysis of a series of 118 cases. J Neurosurg Spine $7(6):$ 587-593.

4. Kim YS, Lee JK, Choi KY, Jae Won Jang (2015) Spinal Burkitt's Lymphoma Mimicking Dumbbell Shape Neurogenic Tumor: A Case Report and Review of the Literature. Korean J Spine 12(3): 221-224.

5. Nagano S, Yokouchi M, Yamamoto T, Kaieda H, Setoguchi T, et al. (2013) Castleman's disease in the retroperitoneal space mimicking a paraspinal schwannoma: a case report. World J Surg Oncol 11: 108.

6. Lee DH, Park CK, Keum DY, Jae Bum Kim, Ilseon Hwang (2012) Leiomyosarcoma of the posterior mediastinum extending into the adjacent spinal canal. Korean J Thorac Cardiovasc Surg 45(3): 192-195.

7. Makis W, Rakheja R, Nahal A, Hickeson M, Lisbona R (2013) Urinary bladder leiomyosarcoma: staging with ${ }^{18} \mathrm{~F}-\mathrm{FDG}$ PET/CT. Clin Nucl Med 38(5): e218-222.
8. Pai M, Yoon SN (2013) 18F-FDG imaging of the primary breast leiomyosarcoma and follow-up lung metastasis. Clin Nucl Med 38(3): e152-154.

9. Zhang R, Tian X, Qin L, Lu D, Shen J (2015) High 18F-FDG uptake for uterine smooth muscle tumor of uncertain malignant potential. Clin Nucl Med 40(4): 349-351.

10. Zhou W, Hua F, Qian J, Bi Y, Guan Y (2017) MRI and FDG PET/CT Findings of Primary Orbit Leiomyosarcoma. Clin Nucl Med 42(1): e71-e74.

11.Xie P, Zhuang H (2017) FDG PET/CT Findings of Primary Hepatic Leiomyosarcoma in an Immunocompetent Pediatric Patient. Clin Nucl Med 42(4): 323-324.

12. Makis W, Brimo F, Probst S (2018) Primary Renal Leiomyosarcoma Presenting with Subcutaneous and Osseous Metastases: Staging and Follow-Up with 18F-FDG PET/CT. Nucl Med Mol Imaging 52(1): 69-73.

13. Wu X, Huang Y, Li Y, Wang H, Jiang L (2019) A Case of Mediastinal Leiomyosarcoma Demonstrated on FDG PET/CT Imaging. Clin Nucl Med 44(3): e158-e160.

14. Macpherson RE, Pratap S, Tyrrell H, Khonsari M, Wilson S, et al. (2018) Retrospective audit of 957 consecutive ${ }^{18} \mathrm{~F}-\mathrm{FDG}$ PET-CT scans compared to CT and MRI in 493 patients with different histological subtypes of bone and soft tissue sarcoma. Clin Sarcoma Res 8: 9. 
ISSN: 2574-1241

DOI: 10.26717/BJSTR.2019.22.003779

Lin Li. Biomed J Sci \& Tech Res

(C) (P) This work is licensed under Creative

Submission Link: https://biomedres.us/submit-manuscript.php

$\begin{array}{ll}\text { BIOMEDICAL } & \text { Assets of Publishing with us } \\ \text { RESEARCHES } & \text { - Global archiving of articles } \\ \text { - Immediate, unrestricted online access } & \text { - Rigorous Peer Review Process } \\ & \text { - Authors Retain Copyrights } \\ & \end{array}$

